\title{
Warm water bathing did not reduce use of pharmacological analgesia during the first stage of labour
}

\author{
Eckert K, Turnbull D, MacLennan A. Immersion in water in the first stage of labor: a randomized controlled trial. Birth \\ 2001 Jun;28:84-93.

\section{QUESTION: In women in labour, does warm water bathing reduce the need for pharmacological pain relief more than no bathing?}

\section{Design}

Randomised (allocation concealed*), partially blinded (data analysts blinded to study group allocation where appropriate),* controlled trial with 8 months of follow up.

\section{Setting}

A maternity tertiary-care referral centre in Adelaide, South Australia, Australia.

\section{Patients}

274 pregnant women (mean age 28 y) who were planning to deliver at the study hospital, were expecting a singleton pregnancy at term, and had no medical or obstetric complications. Exclusion criteria were labour before 37 weeks of gestation, plans to deliver by caesarean section, requirement for continuous electronic fetal monitoring, history of group B streptococcal vaginal colonisation, or need for parenteral narcotic or epidural blockade shortly after admission. All women were included in the analysis.

\section{Intervention}

Women were allocated to warm water bathing $(n=137)$ or routine hospital care $(\mathrm{n}=137)$. Women in the bathing group could have a bath for as long as they liked during the first stage of labour. The bathtubs were in the delivery rooms and were $54 \mathrm{~cm}$ deep; the temperature of the water was maintained at $37^{\circ} \mathrm{C}$. Routine care excluded the use of a bath but allowed a shower. All women were permitted other forms of pain relief, including parenteral analgesia or epidural blockade.

\section{Main outcome measures}

The primary outcome was use of pain relief during the first stage of labour. Secondary outcomes were maternal complications, interventions used in labour and delivery, and neonatal events.

\section{Main results}

40 women $(29 \%)$ in the bathing group did not use the bath, and 36 women (26\%) in the usual care group used the bath. Analysis was by intention to treat. The groups did not differ for use of major pharmacological analgesia (pethidine, fentanyl, or epidural, individually or collectively, $\{p=0.09\} \dagger$ ) (table). The bathing group did not differ from the usual care group for induction (21\% v 20\%; relative risk [RR] $1.07 \%$, CI 0.62 to 1.67 ) or augmentation of labour (32\% v 36\%; RR 0.88 , CI 0.63 to 1.22), duration of labour (460 $v 450 \mathrm{~min},\{\mathrm{p}=0.7609\} \dagger)$, method of delivery (eg, emergency caesarean section
$8.0 \% \cup 6.6 \%,\{\mathrm{p}=0.64\} \uparrow)$, or perineal trauma (eg, second degree tear or greater, $27 \%$ v $33 \%,\{p=0.29\} \dagger)$. The groups did not differ for any neonatal outcome, but when resuscitation measures were combined, newborns in the bathing group required more resuscitation than did those in the usual care group (49\% v 35\%, $\{\mathrm{p}=0.02\} \dagger$ ).

\section{Conclusion}

In women in labour, warm water bathing did not reduce the need for pharmacological pain relief and did not affect maternal or postnatal outcomes.

*See glossary.

$\uparrow \mathrm{p}$ Values calculated from data in article.
Source of funding: Department of Human Services and Women's and Children's Hospital.

For correspondence: Ms $K$ Eckert, Department of Human Services Public and Environmental Health Service, P.O. Box 6, Rundle Mall, Adelaide SA 5000, Australia. Fax +6182267187
Warm water bathing $v$ no bathing for pain relief during first stage of labour:

\begin{tabular}{lllll} 
Outcome & Bathing & No bathing & RRI (95\% CI) & NNH \\
Need for major analgesia & $85 \%$ & $77 \%$ & $10 \%(-1.5$ to 24$)$ & Not significant \\
\hline
\end{tabular}

$\ddagger$ Abbreviations defined in glossary; RRI, $\mathrm{NNH}$, and $\mathrm{Cl}$ calculated from data in article.

\section{COMMENTARY}

While reviewing the study by Eckert et al, I was reminded of Iain Chalmers' article ${ }^{1}$ published almost 20 years ago in which he cited clinicians' reactions to a trial that involved immersing newborns in water. Those who firmly believe in the benefits of water immersion will argue that the length of time spent in the bath was too short, the bath was taken at the wrong time, or that the water was too hot. Similarly, non-believers will jump on any excuse to ban a practice they dislike. As a result of this study by Eckert $e t a l$, at least one Canadian hospital has considered banning bathing during labour because of the effect on babies. This is a misinterpretation of the trial results. Only one neonatal outcome (need for resuscitation) differed significantly between the groups. The trial was not powered to detect differences in important neonatal outcomes, and given the various statistical tests done it could have been a chance finding. I hope that the Cochrane review ${ }^{2}$ will soon be updated to include this trial and a recent Canadian trial. ${ }^{3}$

Women should be informed that a bath during labour is unlikely to affect their use of analgesia or other medical interventions, affect method of delivery, or improve their satisfaction with their birth experience, and that the effects on the fetus are not fully known. Nevertheless, some women will want to have (and will enjoy) a bath. Labour wards that have baths should ensure that adequate infection control practices are in place and that water temperature and the wellbeing of mother and fetus are carefully monitored. But if resources are scarce, how can one justify the costs of installation and maintenance?

Ellen Hodnett, RN, PhD University of Toronto Toronto, Ontario, Canada

1 Chalmers I. Scientific inquiry and authoritarianism in perinatal care and education. Birth 1983;10:151-66.

2 Nikodem VC. Immersion in water in pregnancy, labour and birth. Cochrane Database Syst Rev 2000;(2):CD000111.

3 Rush JP. A randomized controlled trial of the bath in labour. Unpublished PhD dissertation, University of Toronto, 1999. 